\title{
Staff suggest cure for Smithsonian woes
}

\section{Josette Chen}

Scientists at the National Museum of Natural History (NMNH) in Washington have come up their own plan for reorganizing research operations at the Smithsonian Institution, of which the museum is part.

The 13-page plan would divide science at the Smithsonian into three institutes of roughly equal size, dealing with astrophysics, natural sciences and environmental sciences. It would retain close ties between the administration of research and exhibits ties the scientists have accused the Smithsonian's management of trying to break.

The 155-year-old institution has been in turmoil for most of this year as its secretary, Larry Small, clashed with its scientists over his plans to restructure research at the world's largest museum complex.

In May, the dispute led the Smithsonian's Board of Regents to appoint a senior scientific advisory panel, chaired by Jeremy Sabloff of the University of Pennsylvania Museum of Archaeology and Anthropology in Philadelphia (see Nature 411, 624; 2001).

The scientists hope to influence Sabloff's panel when it meets for the first time next month. They propose setting up two Smithsonian-wide bodies: a directorate, comprising the directors of the three proposed institutes, to run research, and a council, including the heads of most research-performing branches, to advise on scientific objectives.

The Smithsonian Astrophysical Observatory at Harvard would make up most of

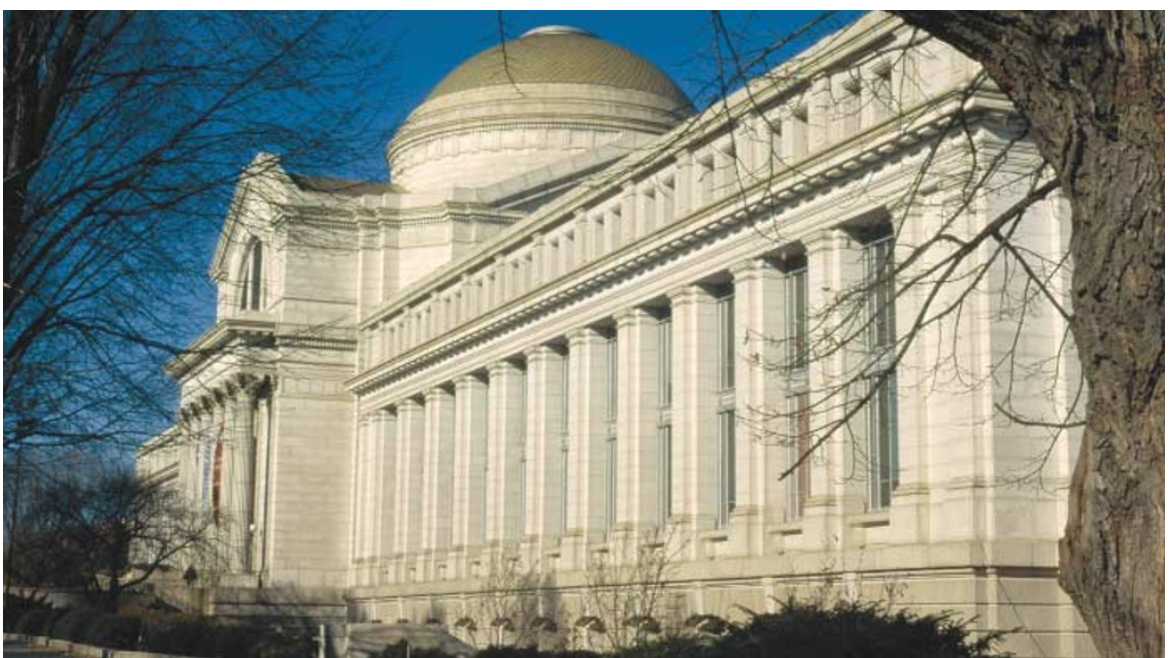

Only natural: researchers hope to retain links between science and exhibitions at the museum.

the astrophysics directorate, and the NMNH would dominate the natural sciences. The environmental-sciences directorate would combine several smaller centres.

Some scientists say the plan protects its authors' interests by giving the NMNH its own directorate. The authors respond that three directorates of about 200 scientists each would allow for efficient administration and benefit all researchers. The authors suggest appointing associate directors for research and for exhibitions at the major Smithsonian museums.

Brian Huber, an NMNH palaeobiologist and one of the authors, says that circulated drafts of the plan were well received.

In response to criticism that their proposal does not go far enough, the authors say that: "Dismantling and reshuffling existing units is not necessarily a prescription for what ails Smithsonian science." They add that radical structural change could lead to years of painful upheaval.

David Umansky, the Smithsonian's director of communications, declined to comment. Sabloff says the proposal has been circulated to the panel members. "I welcome ideas and input from everyone," he says, adding that he would prefer to keep science and exhibits as integrated as possible.

\section{Flickering light raises possibility of changing 'constant'}

David Adam, London

Physicists have reacted with curiosity and scepticism to suggestions that one of the fundamental constants of their discipline may not be so constant after all.

An international team, led by astrophysicist John Webb of the University of New South Wales in Sydney, made the claims after analysing light from bright, distant objects known as quasars. They say their results suggest that the 'fine-structure constant' - a measure of the strength of electromagnetic interactions - has increased by some 0.001\% since the Big Bang.

If true, the finding would be revolutionary. Such constants determine the nature and interaction of matter throughout the Universe. If a shift in the fine-structure constant (also known as alpha) did take place, it would indicate that gravity and the weak and strong nuclear forces can also change over time. Such changes are impossible to explain using conventional theoretical physics and thus open the door

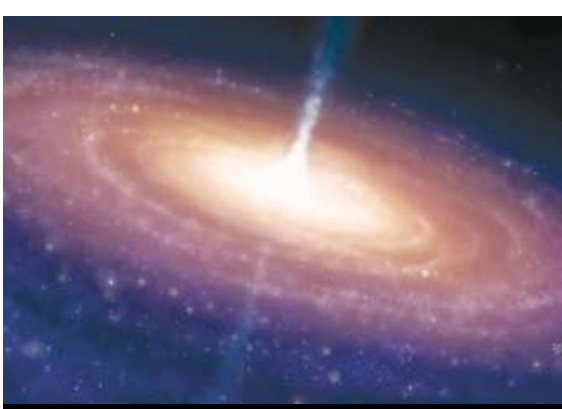

Glowing report: could light from a quasar show that the fine-structure constant has increased?

to rival explanations, including string theory, which invokes extra dimensions.

The result is statistically sound, but other physicists are concerned that a systematic error may be responsible for it. "One cannot see from the paper how they estimate the systematic uncertainties from various effects, only that they claim the errors are smaller than the effects they see," says John Bahcall, an astrophysicist at the Institute for
Advanced Study in Princeton, New Jersey.

Webb's team used data from the Keck telescope in Hawaii to study how clouds of interstellar gas absorb certain wavelengths of quasar light, producing a characteristic signature of dark lines in the spectrum that reaches Earth. They say the spaces between these lines in quasar light (effectively billions of years old) are different from those in similar spectra observed in the $l a b$, and a variation in the fine-structure constant could offer an explanation.

"What we're claiming is that the sample we show is consistent with there being a smaller value of alpha in the past," says John Barrow, a physicist at the University of Cambridge. The team will publish its results on 27 August in Physical Review Letters (87, 091301; 2001).

Bahcall says that the complex analyses required will make it difficult for another group to test the claims. Barrow agrees: "This is not the sort of thing that people will be able to do in the next few months," he says. 